\title{
Model Systems for Flavoenzyme Activity: Interplay of Hydrogen Bonding and Aromatic Stacking in Cofactor Redox Modulation
}

\author{
Mark Gray, ${ }^{\dagger}$ Allan J. Goodman, ${ }^{\dagger}$ Joseph B. Carroll, ${ }^{\dagger}$ Kevin Bardon, ${ }^{\dagger}$ \\ Michael Markey, ${ }^{\dagger}$ Graeme Cooke, ${ }^{\ddagger}$ and Vincent M. Rotello ${ }^{\star}, \dagger$ \\ ${ }^{\dagger}$ Department of Chemistry, University of Massachusetts, Amherst, Massachusetts 01003, and \\ ${ }^{\ddagger}$ Centre for Biomimetic Design and Synthesis, Department of Chemistry, School of \\ Engineering \& Physical Sciences, Heriot-Watt University, Edinburgh, UK EH14 4AS \\ rotello@chem.umass.edu
}

Received Date (will be automatically inserted after manuscript is accepted)

\section{Supplementary Materials}

For ${ }^{1} \mathrm{H}$ NMR titrations, CV data, and experimental for phenyl-DAT and anthracyl-DAT xanthenes with isobutyl flavin please refer to: Breinlinger, E.; Rotello, V. M. J. Am.

Chem. Soc. 1997, 119, 1165-1166.

For ${ }^{1} \mathrm{H}$ NMR titrations, $\mathrm{CV}$ data, and experimental for $p$-thiomethylphenyl-DAT

xanthene with isobutyl flavin please refer to: Breinlinger, E.; Keenan, C.; Rotello, V. M. J. Am. Chem. Soc. 1998, 120, 8606-8609.

Materials and general methods

Solutions utilized in electrochemical experiments were prepared using reagent grade $\mathrm{CH}_{2} \mathrm{Cl}_{2}$ dried via distillation over $\mathrm{CaH}_{2}$. Tetrabutylammonium perchlorate (TBAP, obtained from SACHEM, electrometric grade) was dissolved in $\mathrm{CHCl}_{3}$, washed with distilled water, recrystallized twice from ethyl acetate and dried for several days under 
high vacuum. All chemicals were reagent grade, obtained from Aldrich and used without further purification unless otherwise noted.

\section{Determination of association constants by the ${ }^{1} \mathrm{H}-\mathrm{NMR}$ titration method.}

NMR titration experiments were performed in a non-competitive solvent under constant concentration conditions of N(10)-isobutylflavin at 298 K. Flavin stock solution $\left(\mathrm{CDCl}_{3}\right.$ solvent; $\left.2 \mathrm{~mL}, 5 \mathrm{mM}\right)$ was used to prepare $20 \mathrm{mM}$ solutions of the receptor molecules. A further $600 \square \mathrm{L}$ of the stock solution was transferred to an NMR tube and the spectrum of this solution recorded in a Bruker AC200 $200 \mathrm{MHz}$ NMR spectrometer. Aliquots of the receptor solution were added, with spectra recorded for each addition, and the incremental downfield change in chemical shift of the imide proton resonance noted.

The resulting data was analyzed to reveal the binding constant $K_{\mathrm{a}}$ by application of non-linear least-squares curve fitting. The data for each curve gave excellent agreement with the $1: 1$ binding isotherm, using the relationship

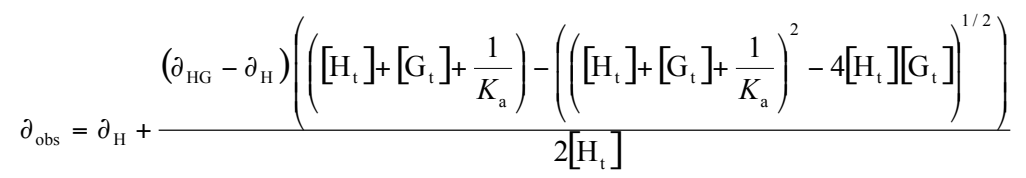

where $\left[G_{t}\right]$ and $\left[H_{t}\right]$, correspond respectively to the total concentrations of guest and host; $\square_{\mathrm{bs}}$, the observed chemical shift, $\square_{\mathrm{H}}$ represents the chemical shift of the imide proton of the host in the absence of guest, and $\square_{H G}$ the chemical shift of the followed proton in the fully bound complex, estimated from extrapolation from the limiting experimental value. 


\section{Electrochemistry}

All electrochemical experiments were carried out on a Cypress System potentiostat. A $1 \mathrm{~mm}$ platinum button and a gold-plated electrode were utilized as working and reference electrodes, respectively. A silver wire pseudo reference electrode was used and all potentials are referenced versus the ferrocene/ferrocenium couple. The sweep rate was $350 \mathrm{mV} / \mathrm{s}$ and the studies were run on an argon-purged temperaturecontrolled cell. Solutions of flavin and the flavin-receptor complexes were prepared maintaining a constant concentration of the cofactor, with the receptors added to saturation. The solutions were degassed by bubbling argon through them for at least 10 minutes, at which time cyclic and square wave voltammograms were recorded.

\section{Receptor Synthesis.}

The synthetic routes chosen for creation of the DAP and DAT based receptors begin from xanthone $\mathbf{1}$ (Scheme 1). This material is alkylated in two steps, first by reaction at the free carbonyl position with methyl aluminum yielding $\mathbf{2}$, then simple Freidel Crafts alkylation with t-butyl chloride to give the more soluble derivative $\mathbf{3}$. Bromination of $\mathbf{3}$ allows $\mathbf{4}$ to be isolated, which after successive lithium halogen exchange and exposure to carbon dioxide gives the acid $\mathbf{5}$. This acid in turn can be further brominated to give $\mathbf{6}$, the last common precursor to the two classes of receptor.

After amide coupling 6 with the desired amine the DAP receptors are isolated by Stille coupling of 7a-d with a tributyltin-derivative of the appropriate recognition unit. The Stille derivative itself takes several steps to prepare, starting from chelidamic acid $\mathbf{8}$. Chelidamic acid was exhaustively brominated in a melt with phosphorous pentabromide, 
which after quenching with methanol gave bis-ester $\mathbf{9}$. From 9 the bis-amide $\mathbf{1 0}$ was obtained after exposure to a hot solution of methanolic ammonia. Hoffman rearrangement of the bis-amide gave diamine 11, which in turn yielded the diamide $\mathbf{1 2}$ upon reaction with propionyl chloride in the presence of triethylamine. The Stille reagent $\mathbf{1 3}$ is isolated after palladium catalysed exchange with bis(tributyltin). The same catalytic system is used to complete the convergent synthesis of the DAP class of receptors by coupling of 13 with 7a-d.

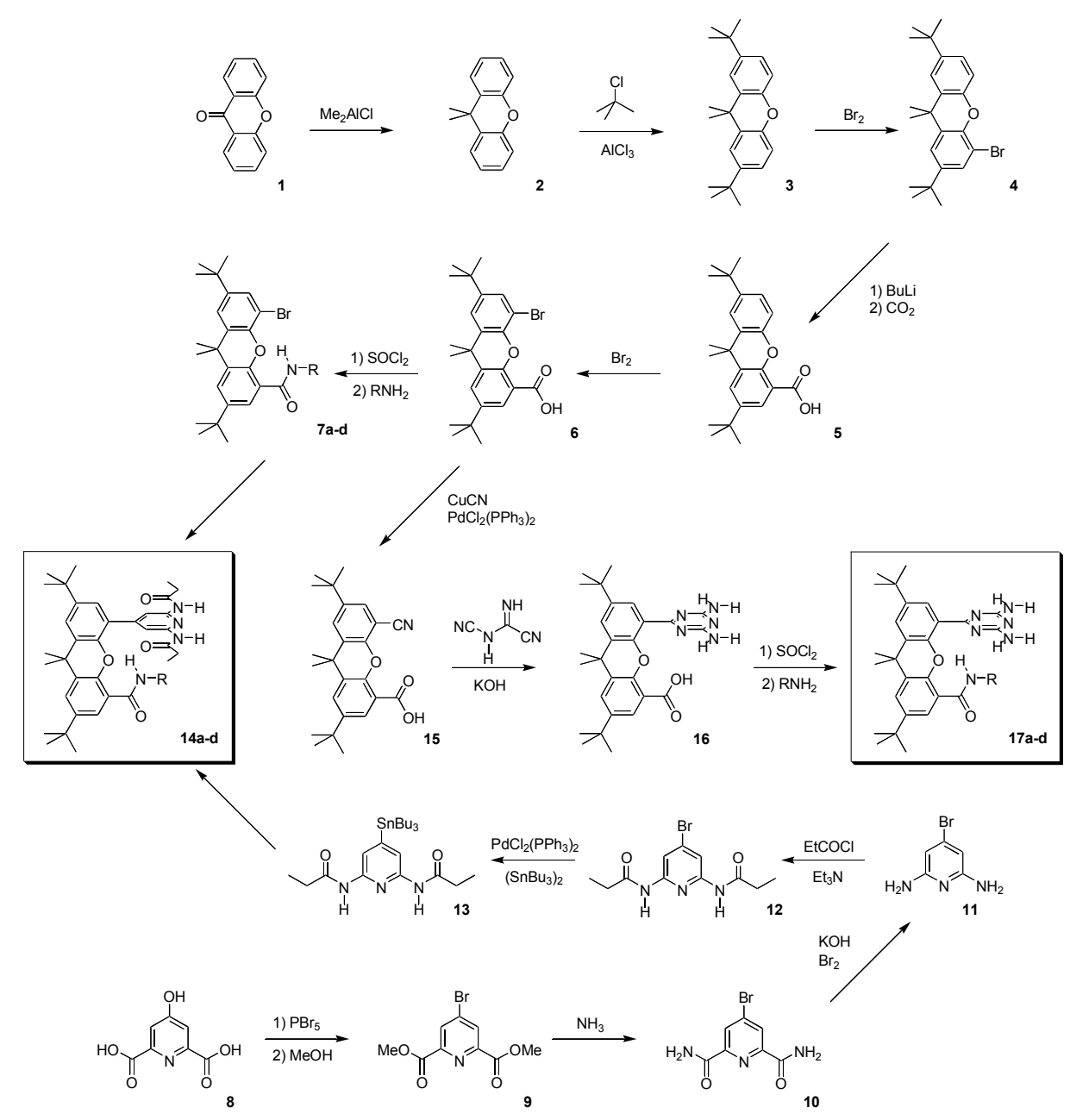

Scheme 1 Synthesis of flavin receptors with imide hydrogen bonding units and orthogonal $\square$-stacking functionality based on a xanthene scaffold. 
The synthesis of the DAT based receptors continues to progress in a linear fashion from intermediate $\mathbf{6}$. Bromine to cyano group exchange upon $\mathbf{6}$ affords $\mathbf{1 5}$ realized through the use of copper cyanide in the presence of a palladium catalyst. The triazine unit is synthesized from the pendant cyano group through reaction with dicyandiamide in the presence of base, giving 16. The desired $\square$-stacking unit is attached in the final step of the synthesis from the acid chloride of $\mathbf{1 6}$ using the appropriate amine.

\section{Synthesis}

The synthesis of compounds $\mathbf{2 - 6}$, and $\mathbf{1 5 - 1 7} \mathbf{d}$ have been reported previously in: a) Goodman, A.; Breinlinger, E.; Ober, M.; Rotello, V. M. J. Am. Chem. Soc. 2001, 123, 6213-6214. b) Breinlinger, E.; Rotello, V. M. J. Am. Chem. Soc. 1997, 119, 1165-1166. c) Breinlinger, E.; Keenan, C.; Rotello, V. M. J. Am. Chem. Soc. 1998, 120, 8606-8609.

\section{Bromo-amides 7a-d (Representative).}

The xanthene acid $6(0.2 \mathrm{~g}, 0.45 \mathrm{mmol})$, was dissolved in thionyl chloride $(5 \mathrm{~mL})$ at room temperature and the resulting solution cooled to $0{ }^{\circ} \mathrm{C} .1$ drop of dimethylformamide was then added and formation of the acid chloride was monitored via TLC as the reaction mixture was allowed to return to room temperature. Upon complete formation of the acid chloride the excess thionyl chloride was removed under reduced pressure. Methylene chloride $(5 \mathrm{~mL})$ was added to dilute the solution, which was then in turn added dropwise to a mixture of amine $(0.5 \mathrm{mmol})$, triethylamine $(0.5 \mathrm{mmol})$ and DMAP (catalytic) in methylene chloride $(5 \mathrm{~mL})$. Progress of the reaction was monitored by TLC. Upon completion the reaction mixture was extracted with saturated sodium 
bicarbonate solution $(10 \mathrm{~mL})$, hydrochloric acid $(0.1 \mathrm{M}, 10 \mathrm{~mL})$ and brine $(10 \mathrm{~mL})$. The remaining organic portion was dried over anhydrous sodium sulfate, and after filtration evaporated onto silica gel. The desired compound was isolated after silica flash column chromatography with hexanes and ethyl acetate as eluents. 7a (phenyl amide) Yield 78\%, NMR Figure 1, IR Figure 2. 7b (phenyl-p-thiomethyl amide) Yield 81\%, NMR Figure 3.7c (anthracene amide) Yield 72\% NMR Figure 4, IR Figure 5.7d (azo amide) Yield 47\%, NMR Figure 6, IR Figure 7.

\section{4-bromopyridine-2,6-bismethylester (9).}

Phosphorous pentabromide (4.2 g) and chelidamic acid 8 (0.5 g) were charged into a flame dried, argon purged $100 \mathrm{~mL}$ rbf equipped with magnetic stirbar. The vessel was subsequently fitted with a reflux condenser then heated to $90{ }^{\circ} \mathrm{C}$ and the resulting melt stirred at this temperature for $3 \mathrm{~h}$. After allowing the reaction mixture to return to room temperature, the residue was taken up in chloroform $(150 \mathrm{~mL})$ and the resulting

solution filtered. The filtrate was cooled to $0{ }^{\circ} \mathrm{C}$, whereupon methanol $(15 \mathrm{~mL})$ was added dropwise over a $1 \mathrm{~h}$ period. The solution was then concentrated to one third of the previous volume under reduced pressure then refrigerated overnight. The precipitate formed was collected via filtration and washed with cold methanol followed by hexanes. Yield 70\%, NMR Figure 8, IR Figure 9.

\section{4-bromopyridine-2,6-bisamide (10).}

The 4-bromopyridine-2,6-bismethylester 9 was dissolved in a minimum volume of hot methanol. A stream of ammonia was slowly passed through the solution for $3 \mathrm{~h}$. 
Removal of the solvent in vacuo gave the desired product, which was subsequently used without further purification. Yield 100\%, NMR Figure 10, IR Figure 11.

\section{4-bromo-2,6-diaminopyridine (11).}

Bromine $(0.085 \mathrm{~mL})$ was added to a $5 \mathrm{M}$ solution of potassium hydroxide (10 $\mathrm{mL})$ at $0{ }^{\circ} \mathrm{C}$ and the mixture stirred for $1 \mathrm{~h} .4$-bromopyridine-2,6-bisamide $\mathbf{1 0}(0.165 \mathrm{~g})$ was then added and stirring continued at $0{ }^{\circ} \mathrm{C}$ until complete dissolution of this material occurred. The reaction mixture was then heated for $4 \mathrm{~h}$ using an oil-bath preheated to 90 ${ }^{\circ} \mathrm{C}$. Upon cooling to RT the residue was extracted with methylene chloride $(5 \times 50 \mathrm{~mL})$ and the combined organic portions evaporated to dryness under reduced pressure. The desired material was obtained by sublimation of this crude material. Yield 80\%, NMR Figure 12, IR Figure 13.

\section{4-bromo-2,6-dipropamidopyridine (12).}

4-bromo-2,6-diaminopyridine $11(0.322 \mathrm{~g})$ and triethylamine $(0.5 \mathrm{~mL})$ were dissolved in methyene chloride $(20 \mathrm{~mL})$. To this mixture a solution of propionyl chloride $(0.32 \mathrm{~mL})$ in methylene chloride was added dropwise. Progress of the reaction was monitored by TLC. Upon completion the reaction mixture was extracted with saturated sodium bicarbonate solution $(10 \mathrm{~mL})$, hydrochloric acid $(0.1 \mathrm{M}, 10 \mathrm{~mL})$ and brine $(10$ $\mathrm{mL}$ ). The remaining organic portion was dried over anhydrous sodium sulfate, and after filtration evaporated onto silica gel. The desired compound was isolated after silica flash column chromatography with hexanes and ethyl acetate as eluants. Yield 90\%, NMR

Figure 14, IR Figure 15. 


\section{2,6-dipropamidopyridine-4-tributyltin (13).}

4-bromo-2,6-dipropamidopyridine 12 (0.300 g), bis(tributyltin) (1.5 mL) and dichloropalladium(bistriphenylphosphine) $(0.008 \mathrm{~g})$ were refluxed in toluene $(6 \mathrm{~mL})$ for 3 h. After cooling to RT the reaction mixture was added to a column of silica gel. Elution with hexanes removed unreacted bis(tributyltin), further elution with $10 \%$ ethyl acetate in hexanes resulted in elution of the desired compound. Yield 80\%, NMR Figure 16, IR Figure 17.

\section{Stille couplings yielding 14a-d (representative).}

2,6-dipropamidopyridine-4-tributyltin 13 (0.050 g), amides 7a-d (1.2 eq) and dichloropalladium(bistriphenylphosphine) (cat.) were refluxed in toluene $(2.5 \mathrm{~mL})$ for 3 h. After cooling to RT the reaction mixture was added to a column of silica gel. Elution with ethyl acetate in hexanes resulted in isolation of the desired compounds. 14a (phenyl DAP) Yield 35\% NMR Figure 18. 14b (phenyl-p-thiomethyl DAP) Yield 27\%, NMR Figure 19, IR Figure 20. 14c (anthracene DAP) Yield 20\%, NMR Figure 21, IR Figure 22. 14d (azo DAP) Yield 29\%, NMR Figure 23, IR Figure 24. 


\section{Spectral Data}

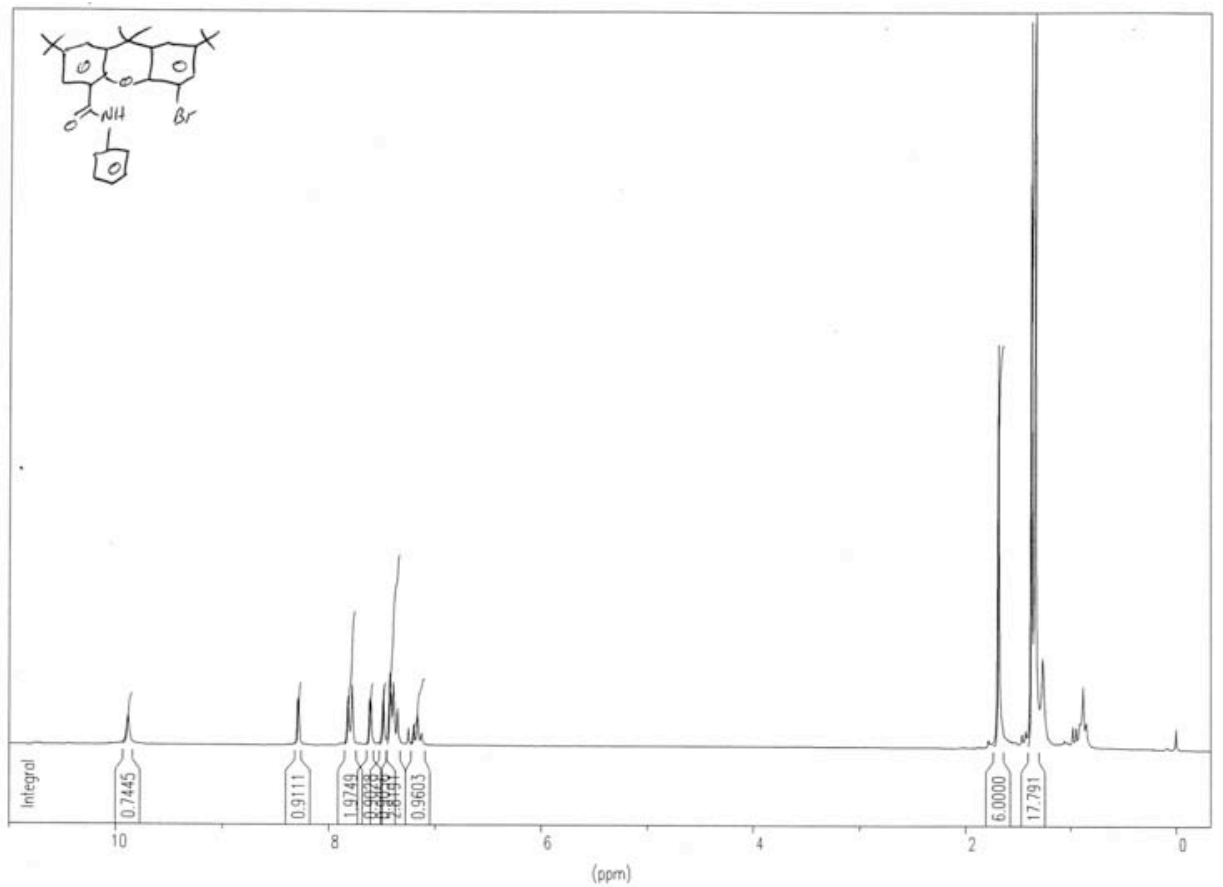

Figure 1 NMR of compound 7a.

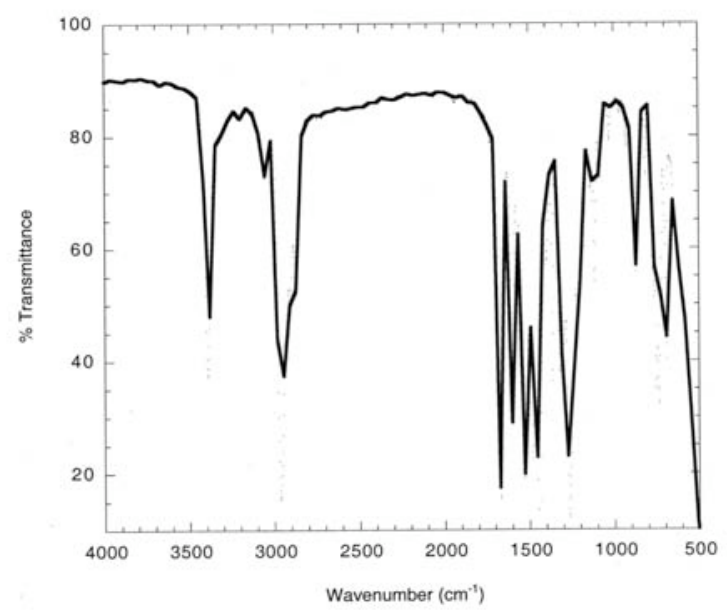

Figure 2 IR spectrum of compound 7a. 


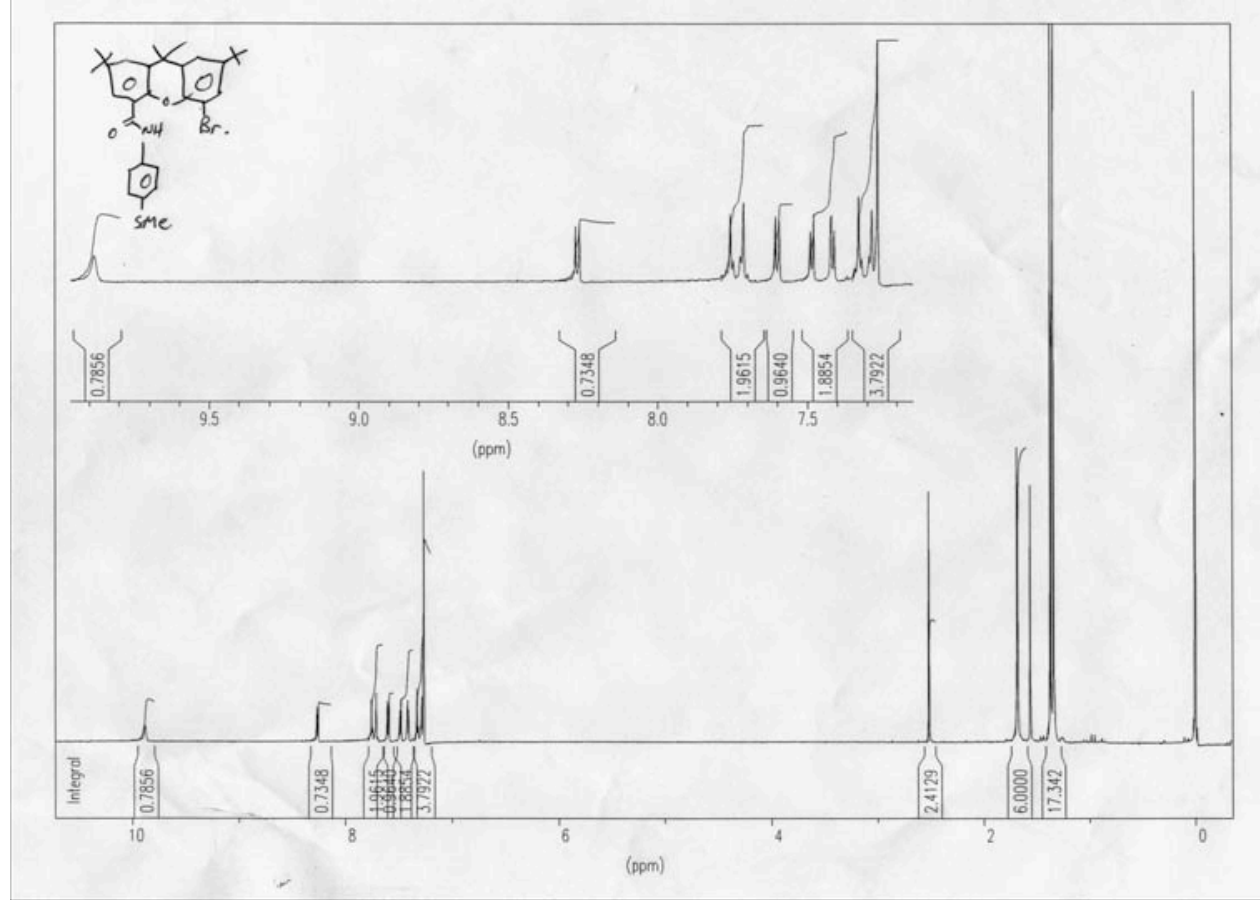

Figure 3 NMR of compound $\mathbf{7 b}$.

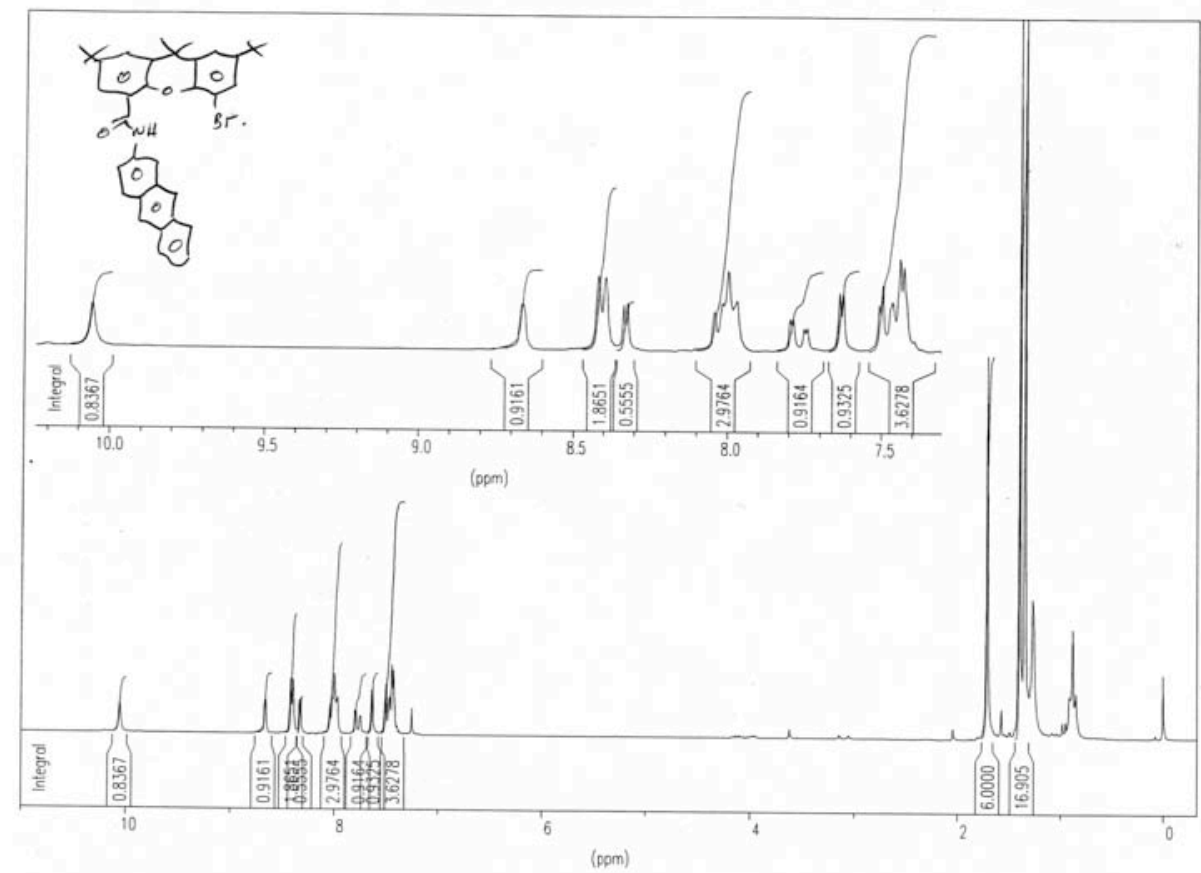

Figure 4 NMR of compound 7c 


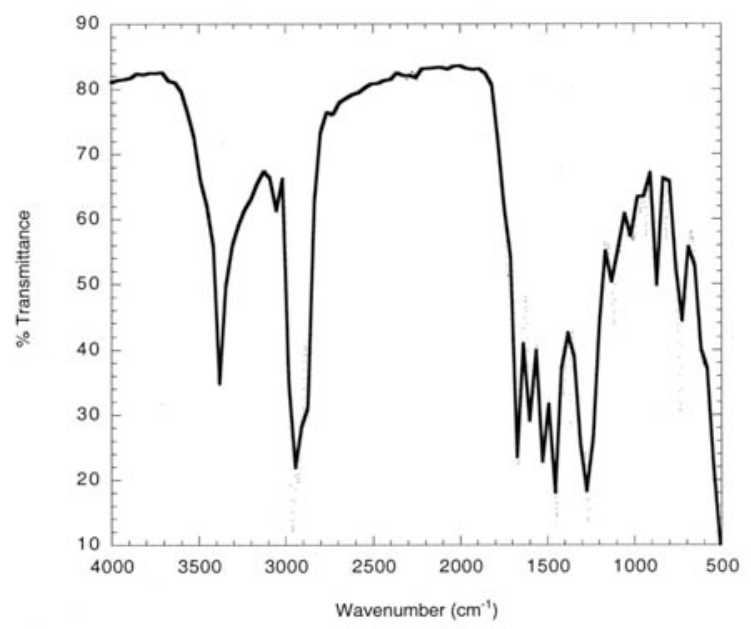

Figure 5 IR spectrum of compound 7c.

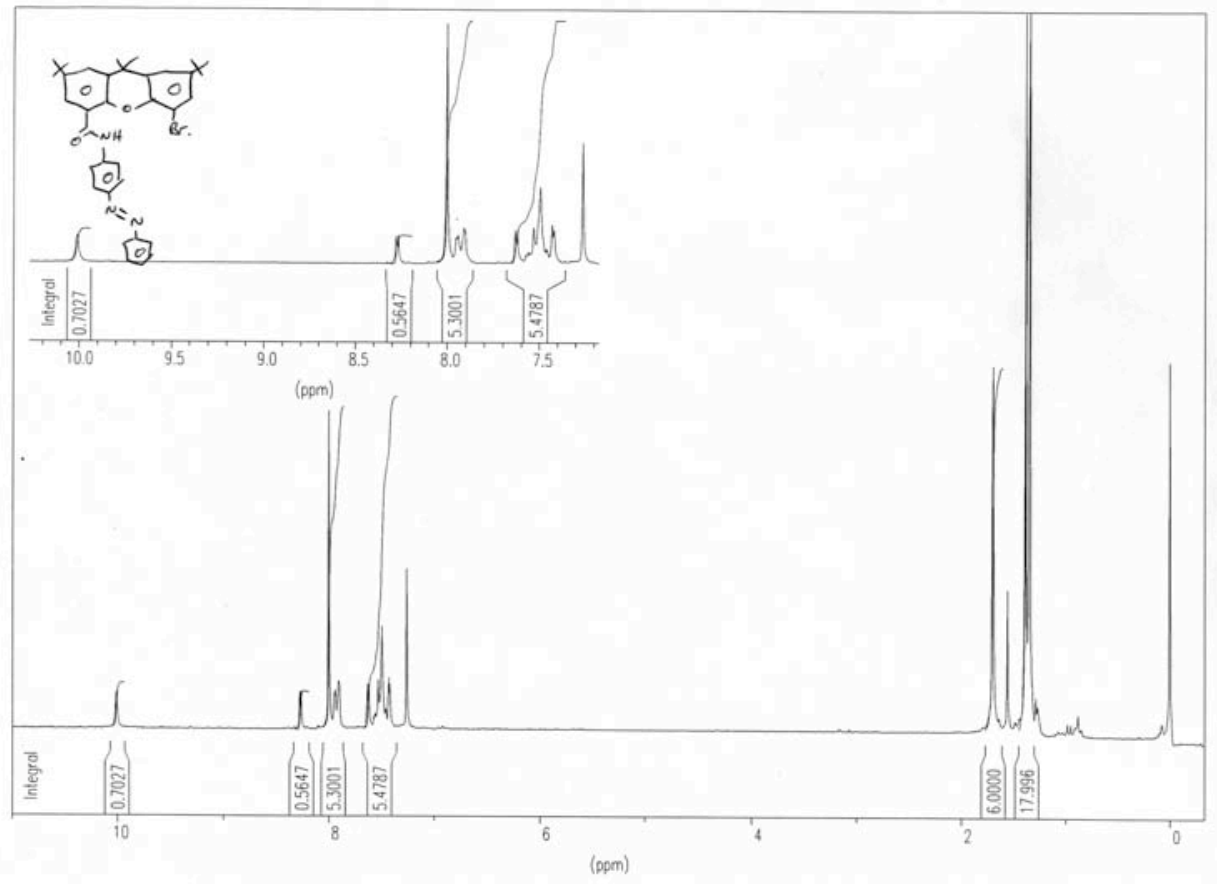

Figure 6 NMR of compound 7d. 


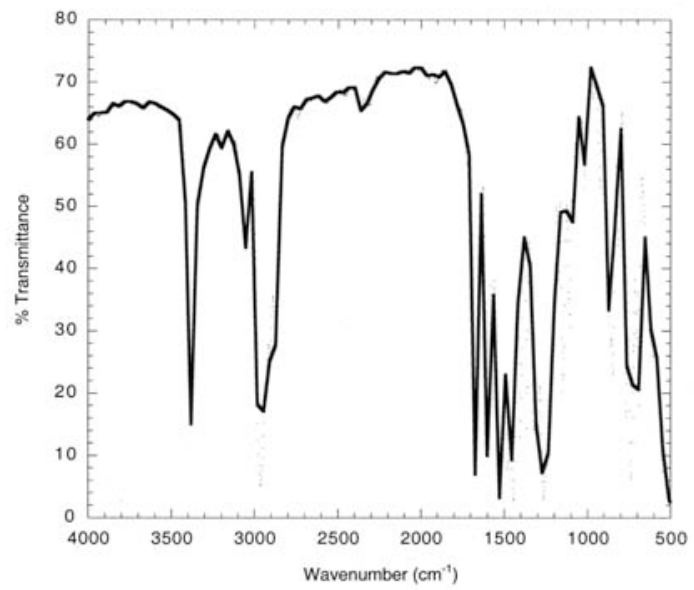

Figure 7 IR spectrum of compound Td.

$m g-2-149, b 4 \mathrm{hi} \mathrm{voc}$, in dmso- $-d 6,2 / 2 / 00$
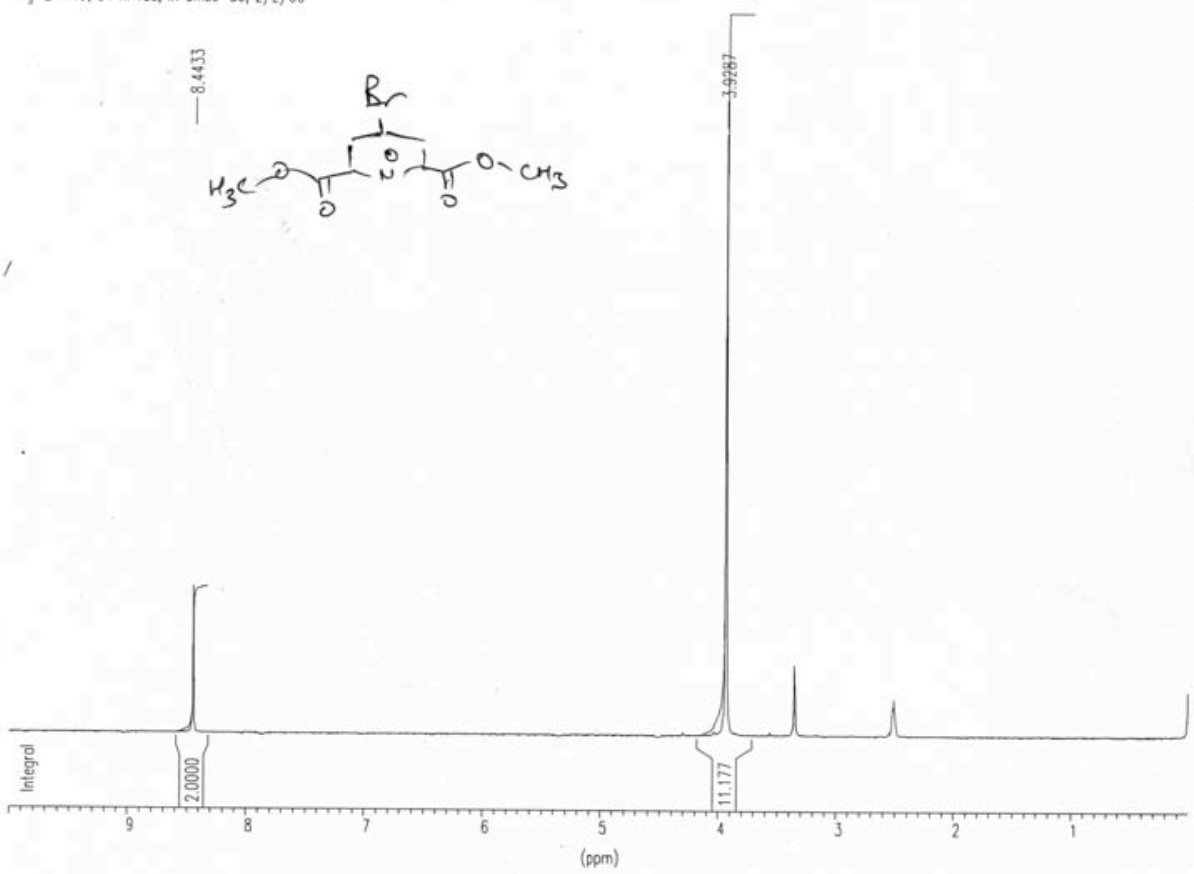

Figure 8 NMR of compound 9. 


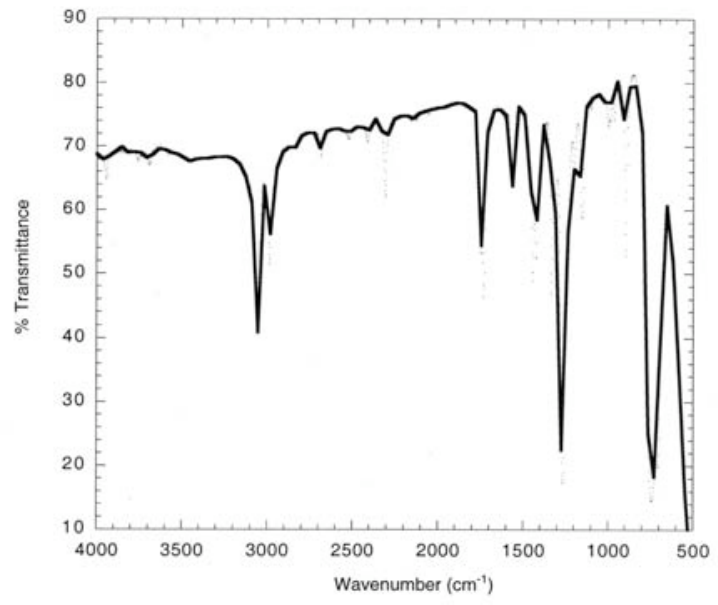

Figure 9 IR spectrum of compound 9.

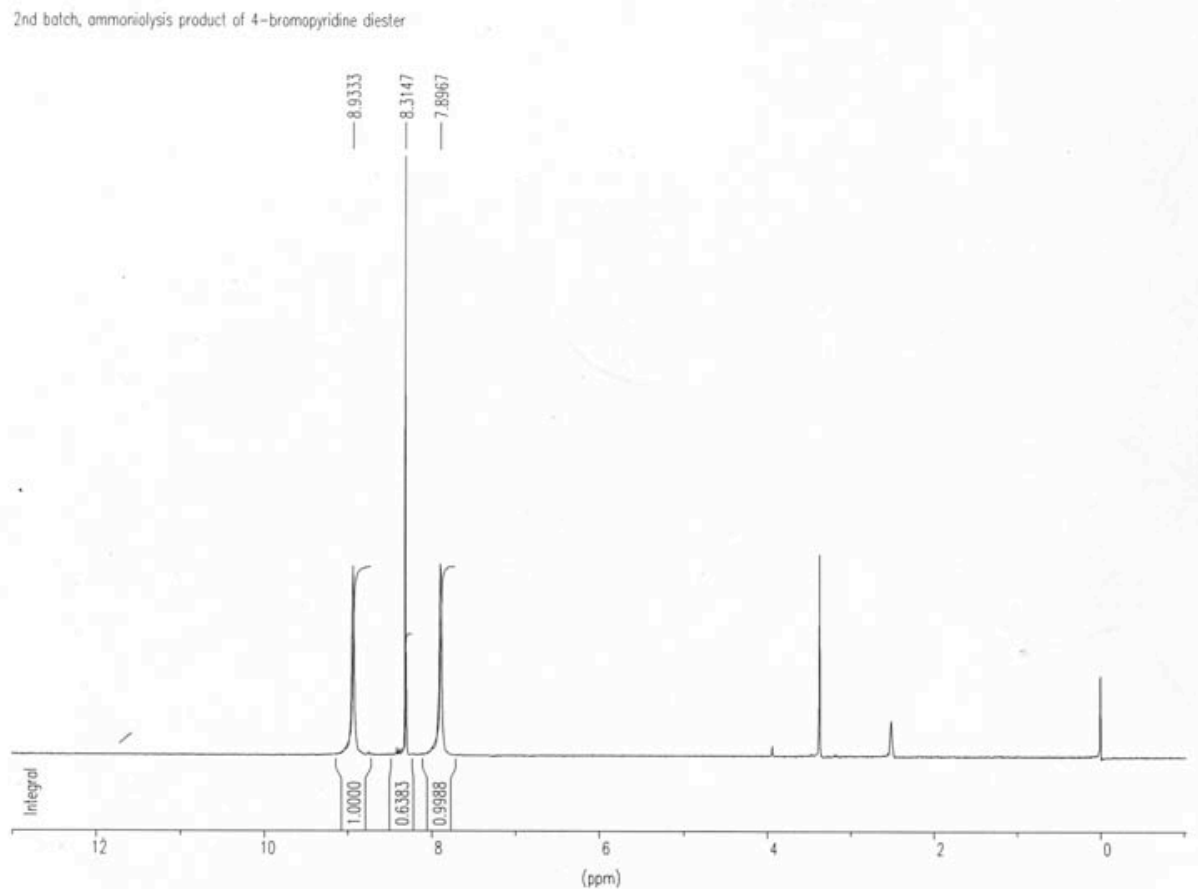

Figure 10 NMR of compound 10. 


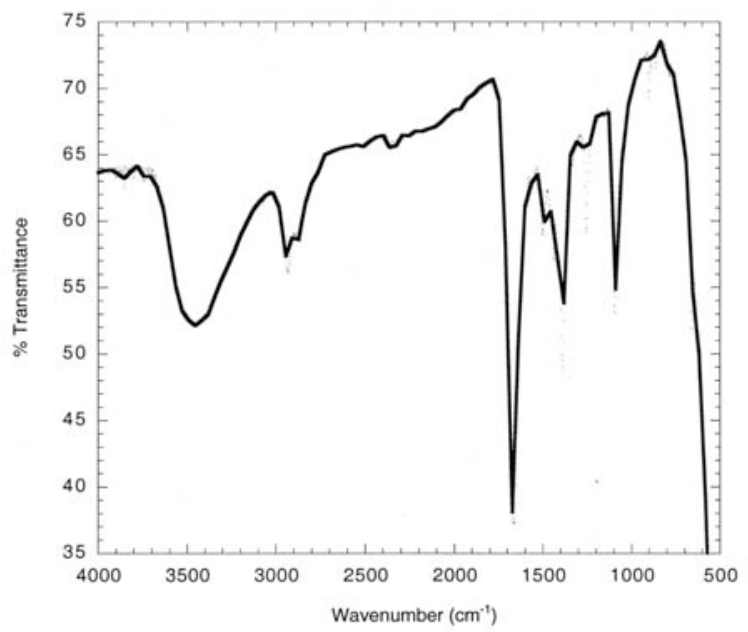

Figure 11 IR spectrum of compound 10.

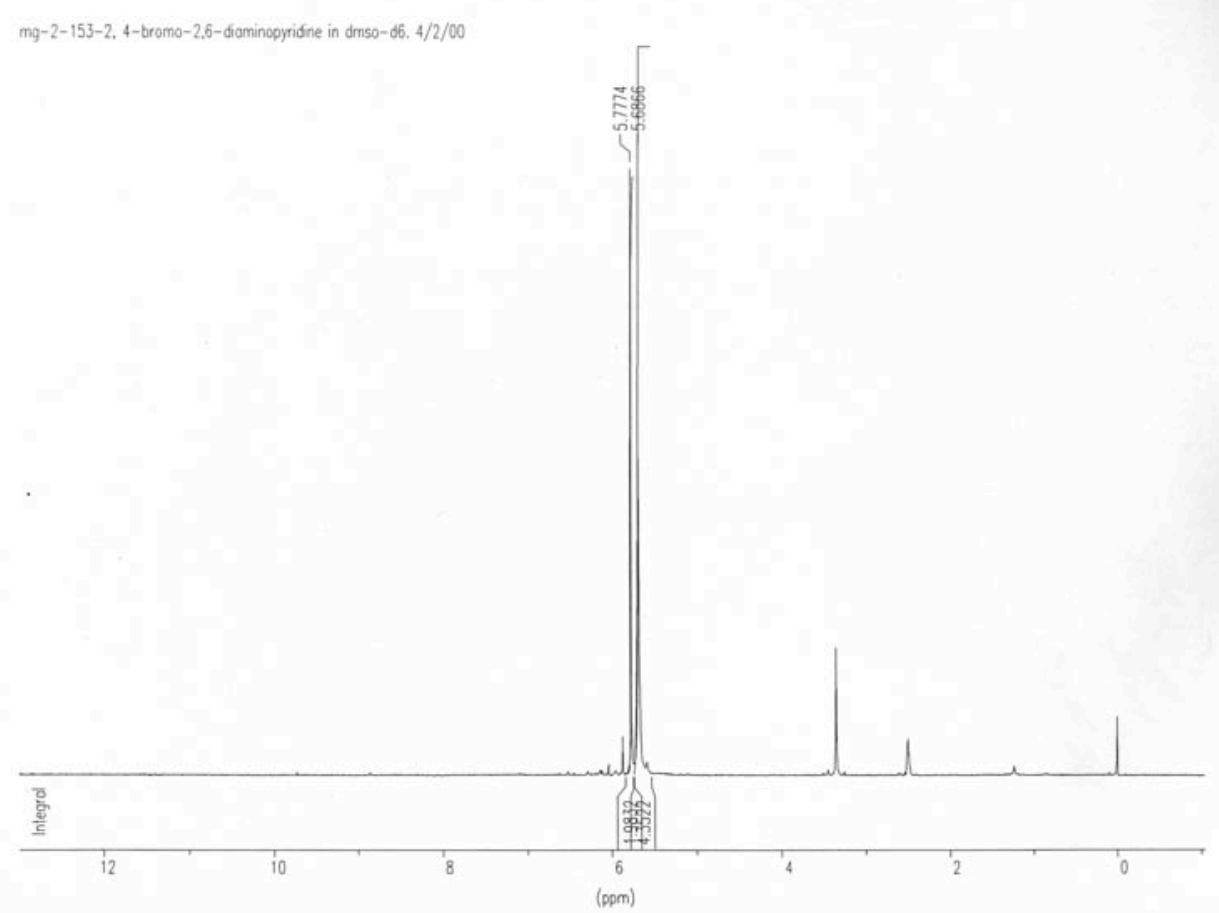

Figure 12 NMR of compound 11. 


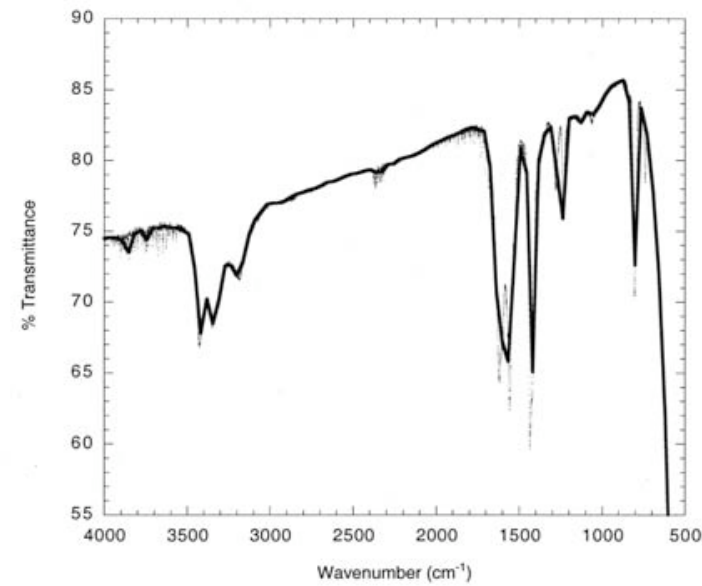

Figure 13 IR spectrum of compound 11.

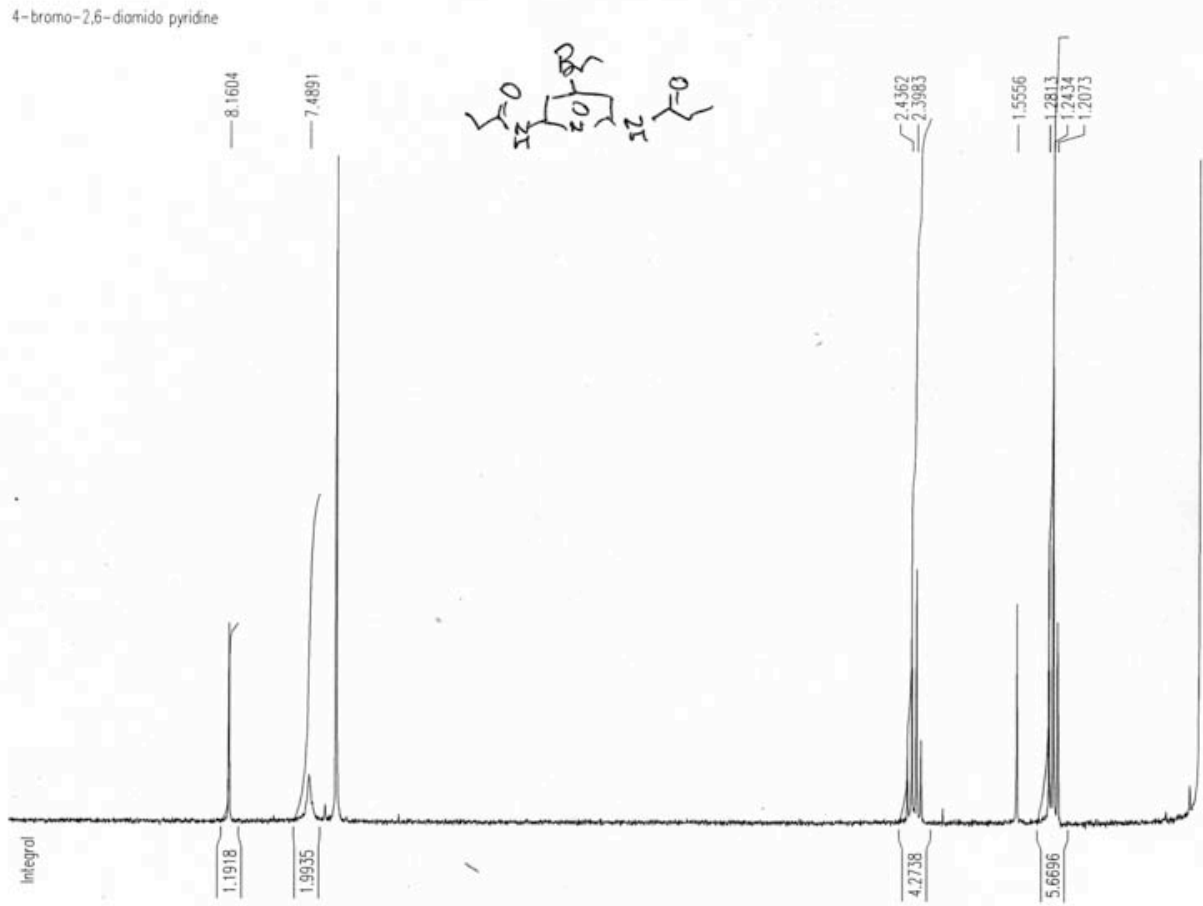

Figure 14 NMR of compound 12. 


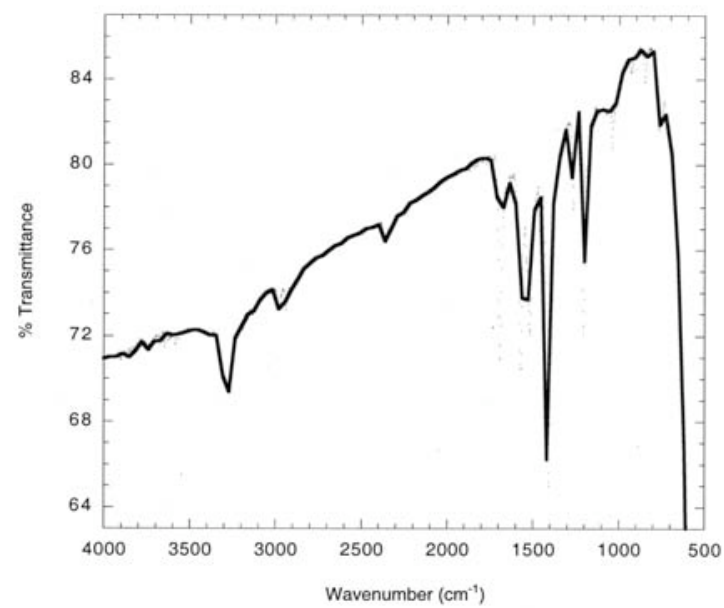

Figure 15 IR spectrum of compound 12.

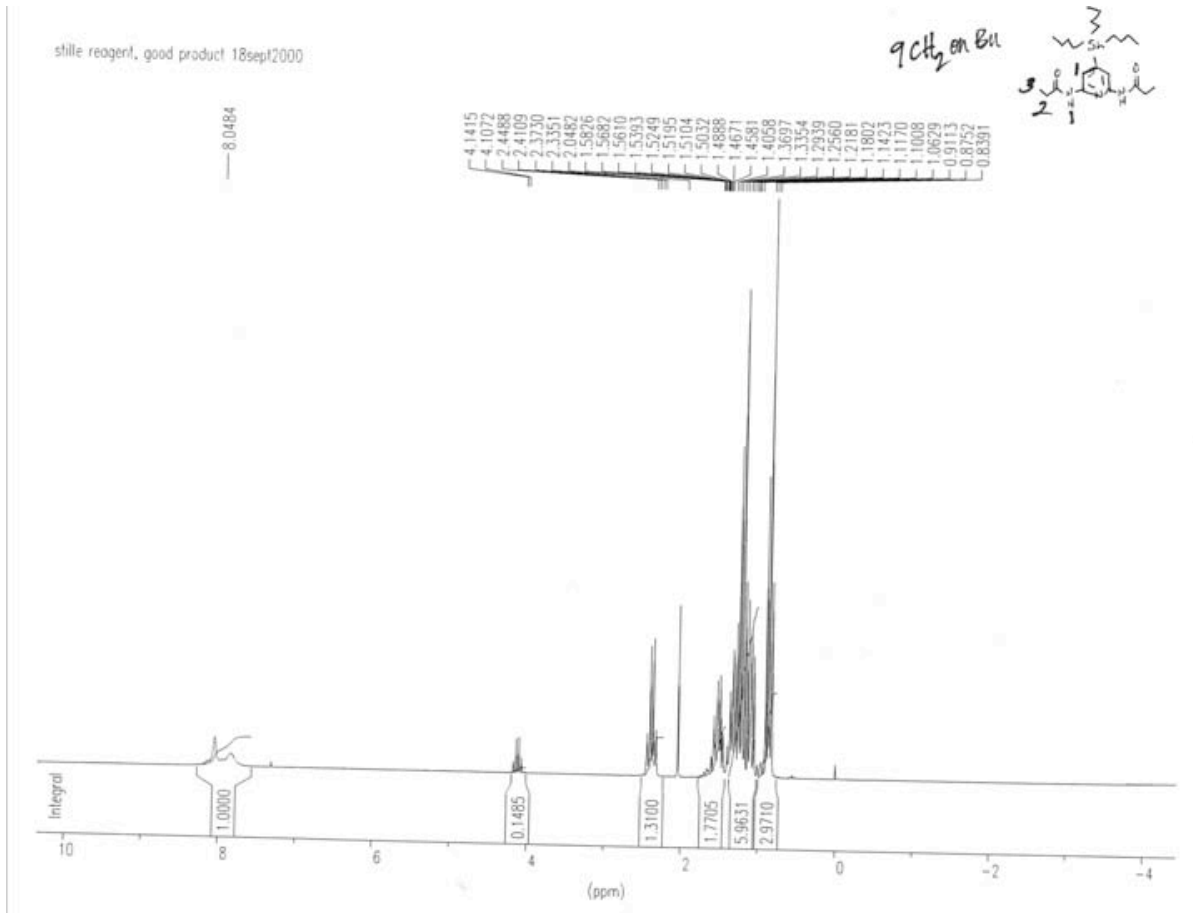

Figure 16NMR of compound 13. 


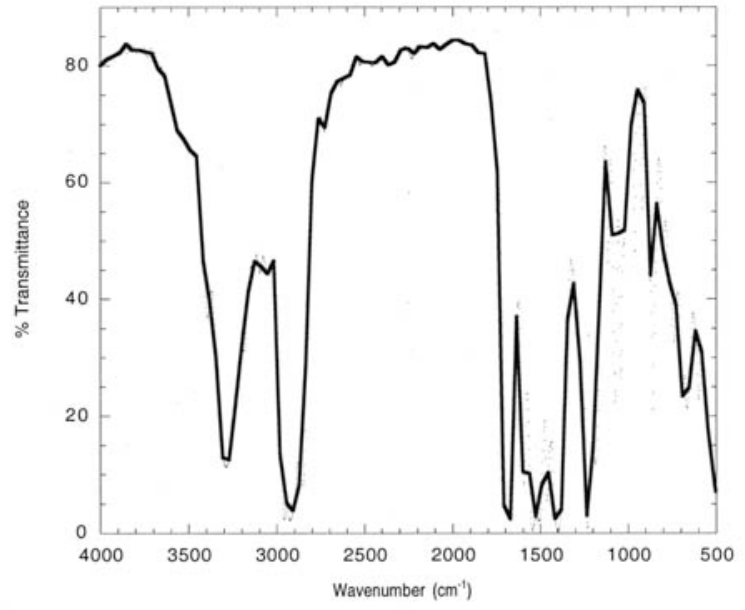

Figure 17 IR spectrum of compound 13.

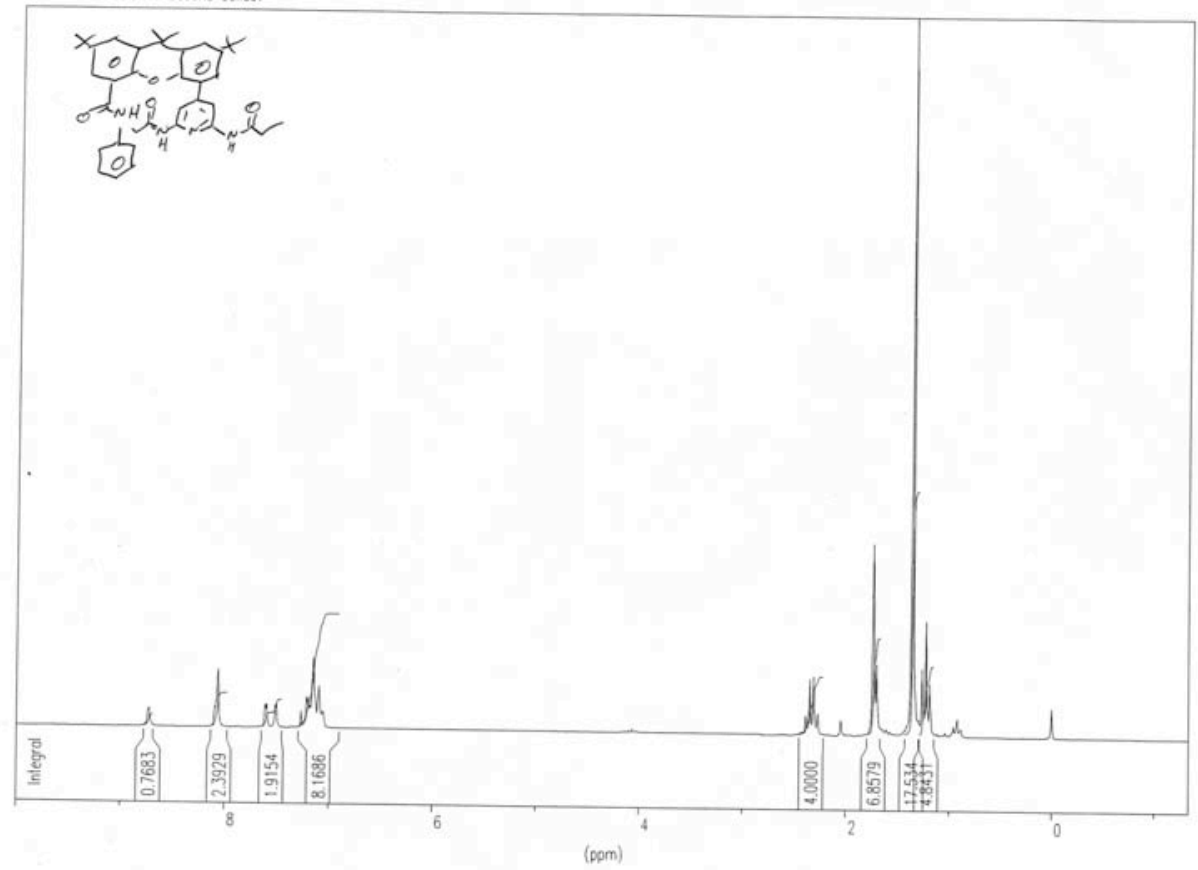

Figure 18 NMR of compound 14a. 


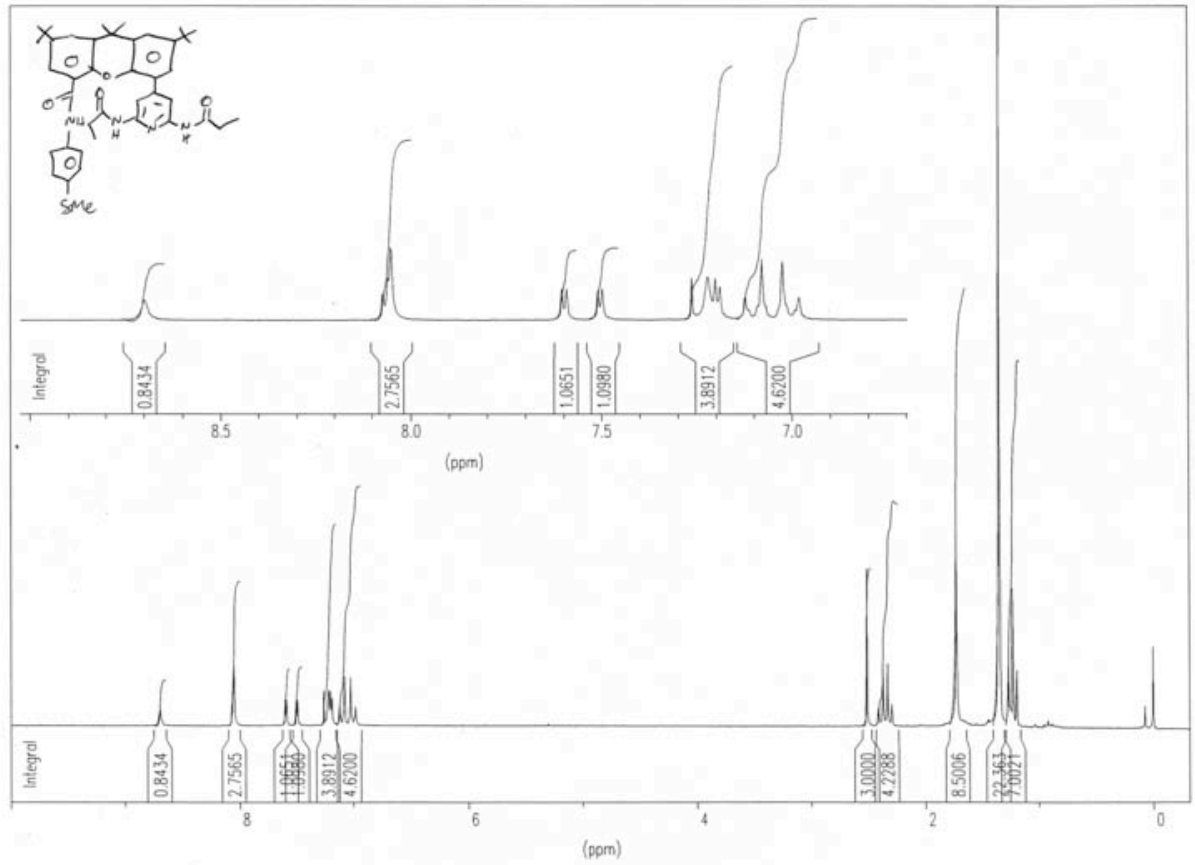

Figure 19 NMR of compound 14b.

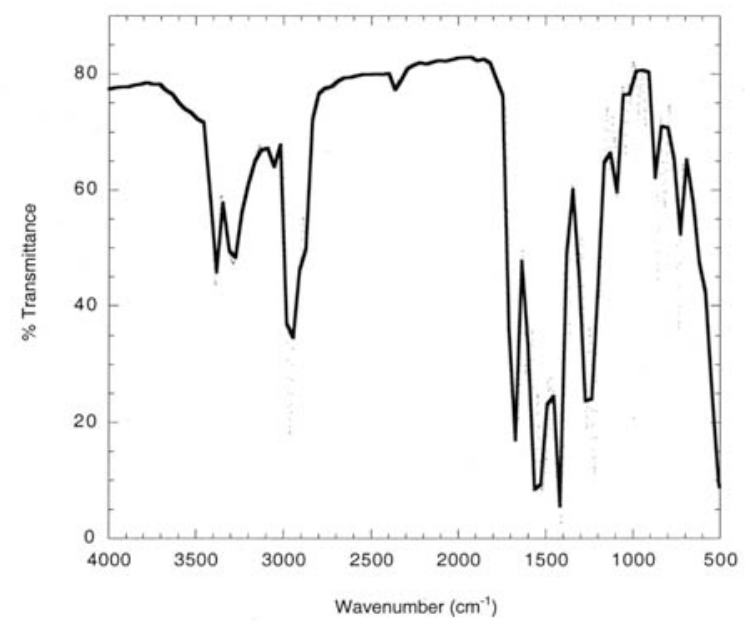

Figure 20 IR spectrum of compound $\mathbf{1 4 b}$. 


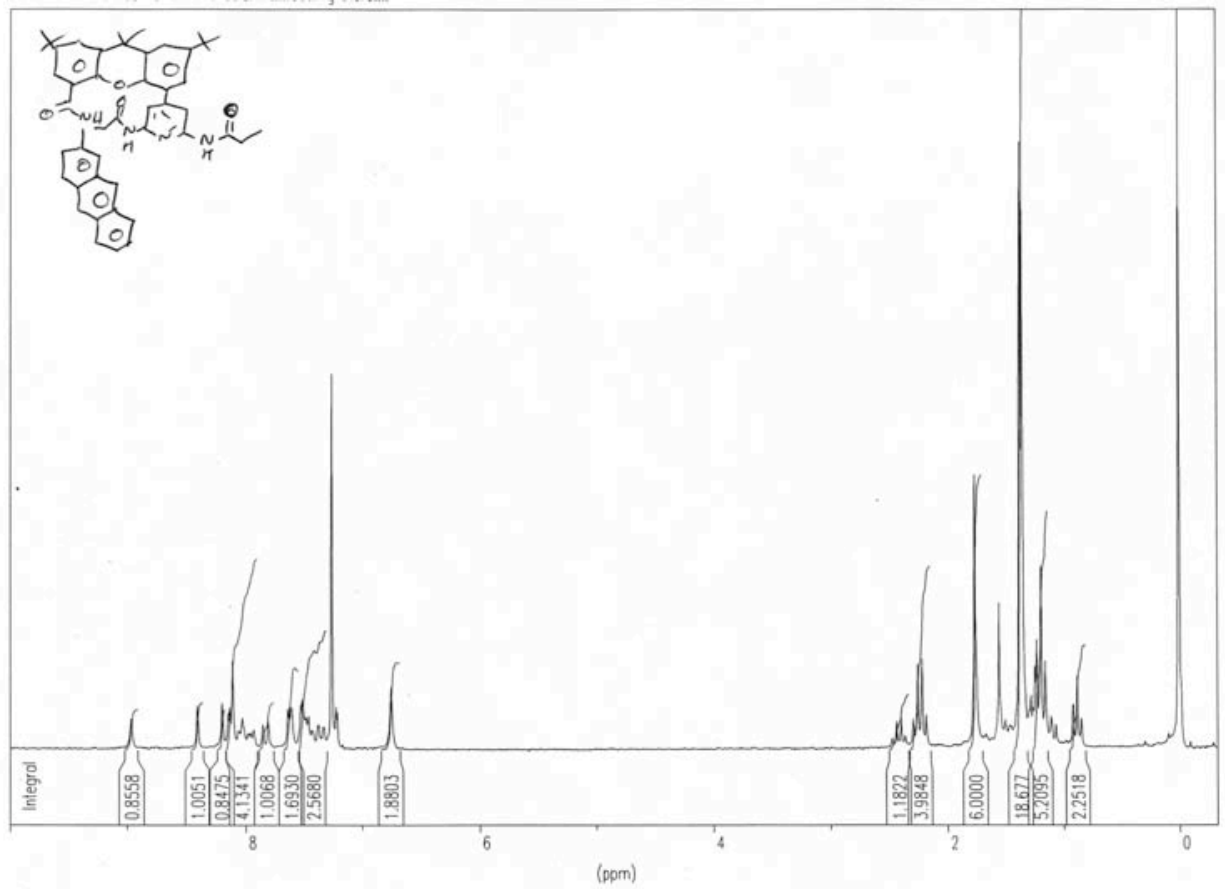

Figure 21 NMR of compound 14c.

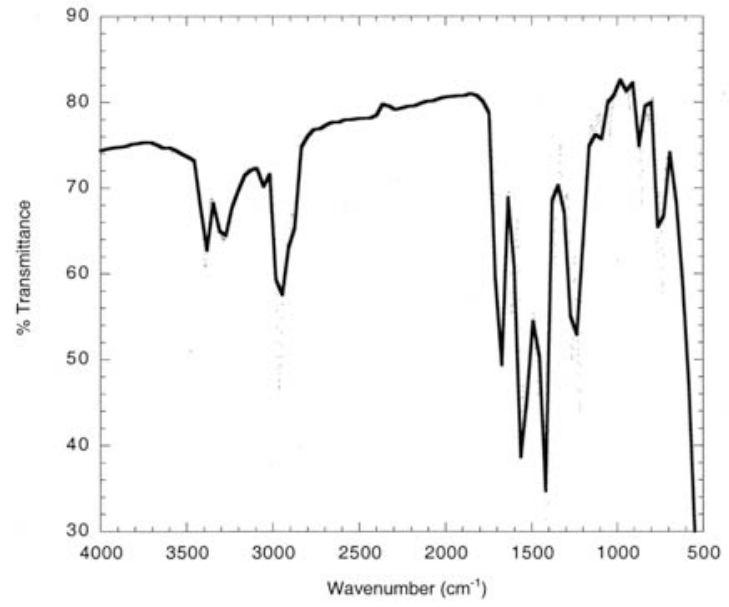

Figure 22 IR spectrum of compound 14c. 


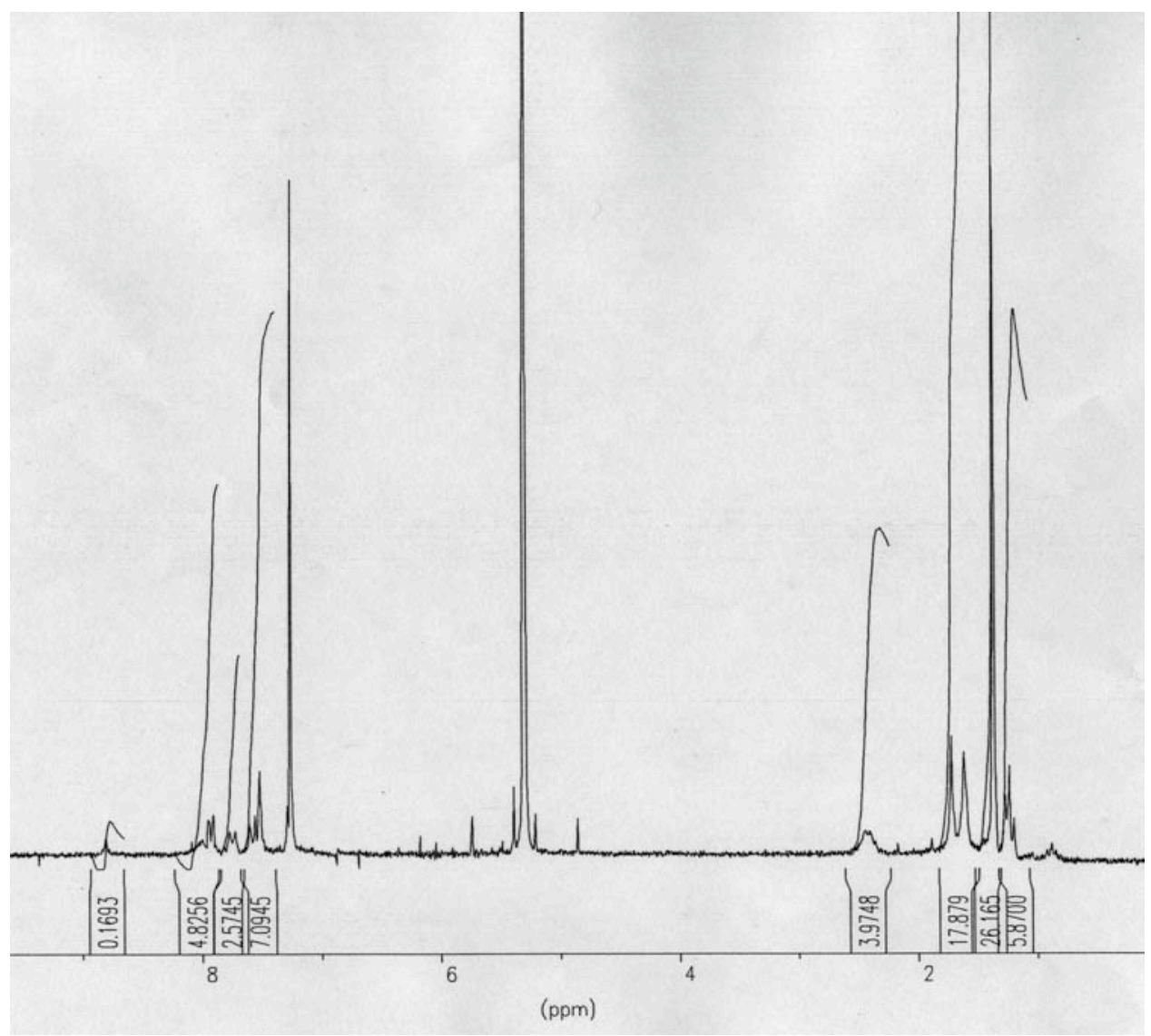

Figure 23 NMR of compound 14d.

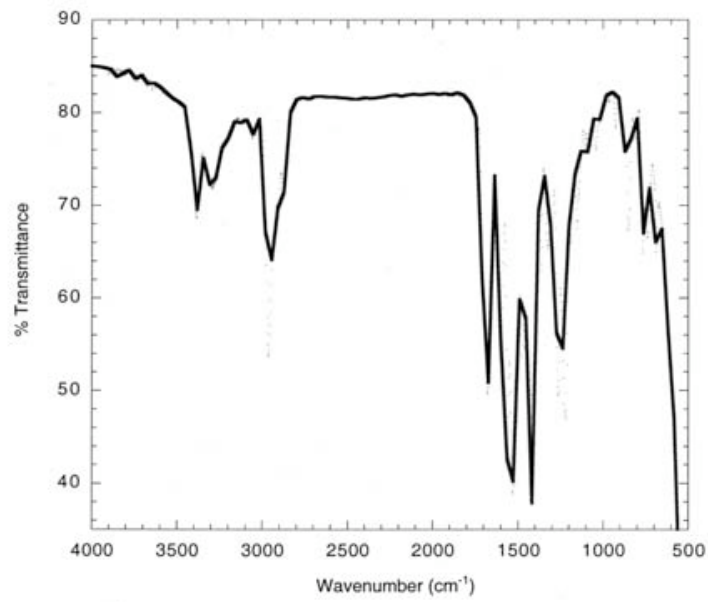

Figure 24 IR spectrum of compound 14d. 


\section{High Resolution Mass Spectrometry (HRMS)}

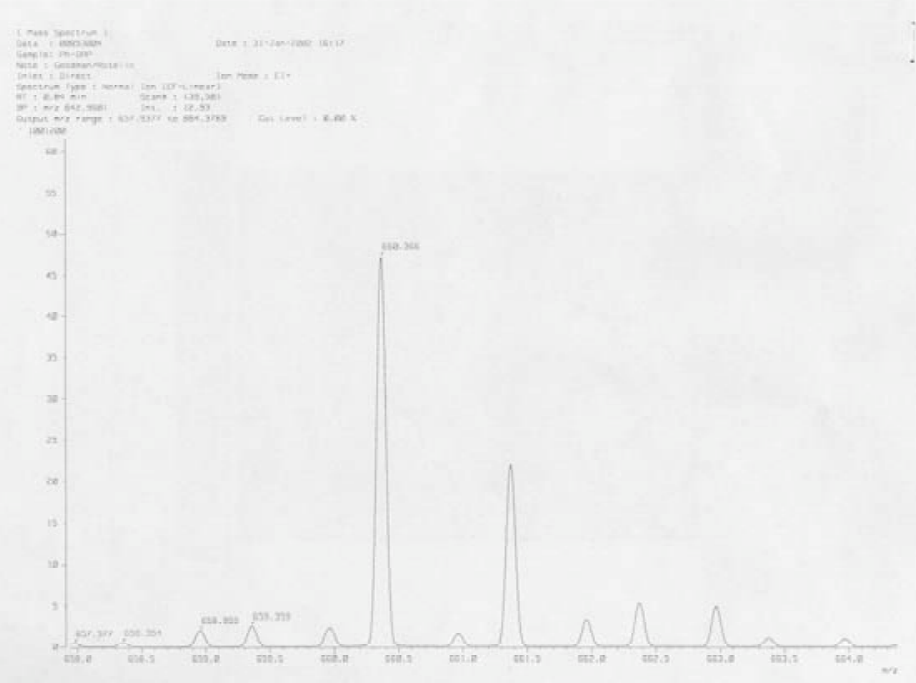

Compound 14a, (phenyl-DAP) HREI, MW 660.8565, m/z 660.3676

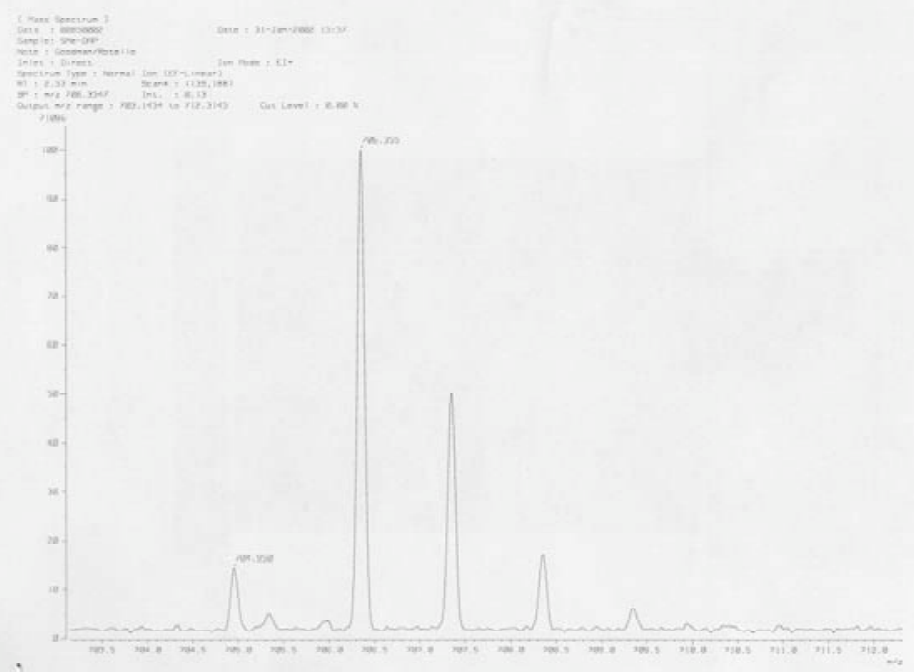

Compound 14b (phenyl-p-thiomethyl-DAP) HREI, MW 706.9494, m/z 706.3553 


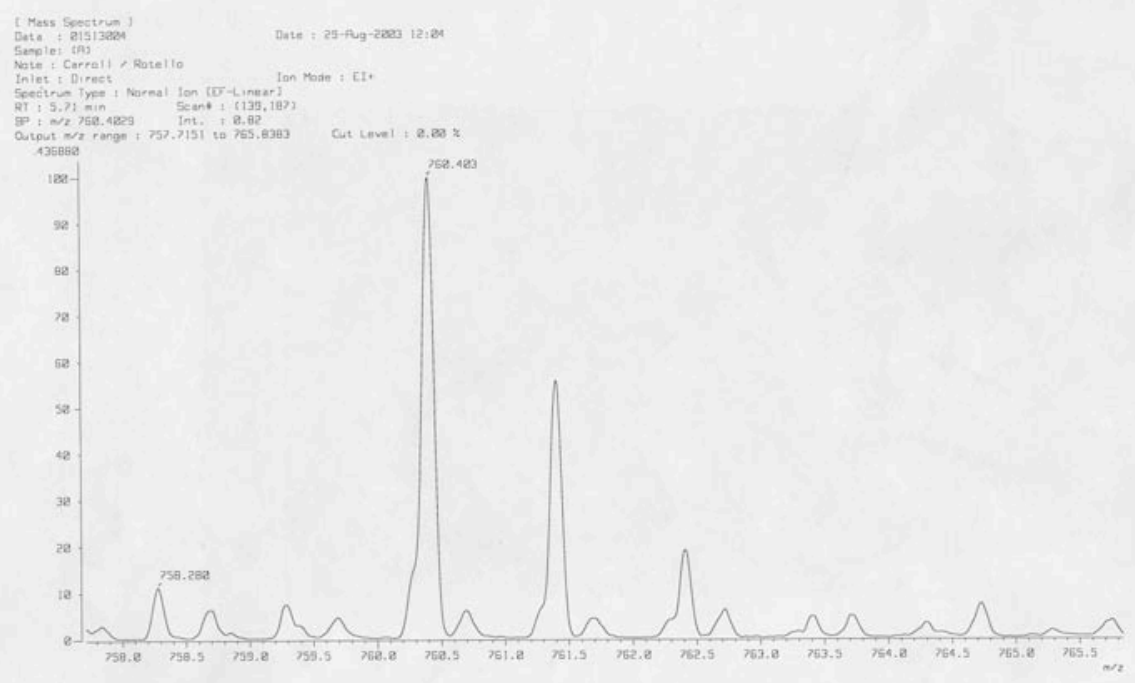

Compound 14c (anthracyl-DAP) HRFAB, MW 760.9763, m/z 760.3989

\section{${ }^{1}$ HNMR titrations}

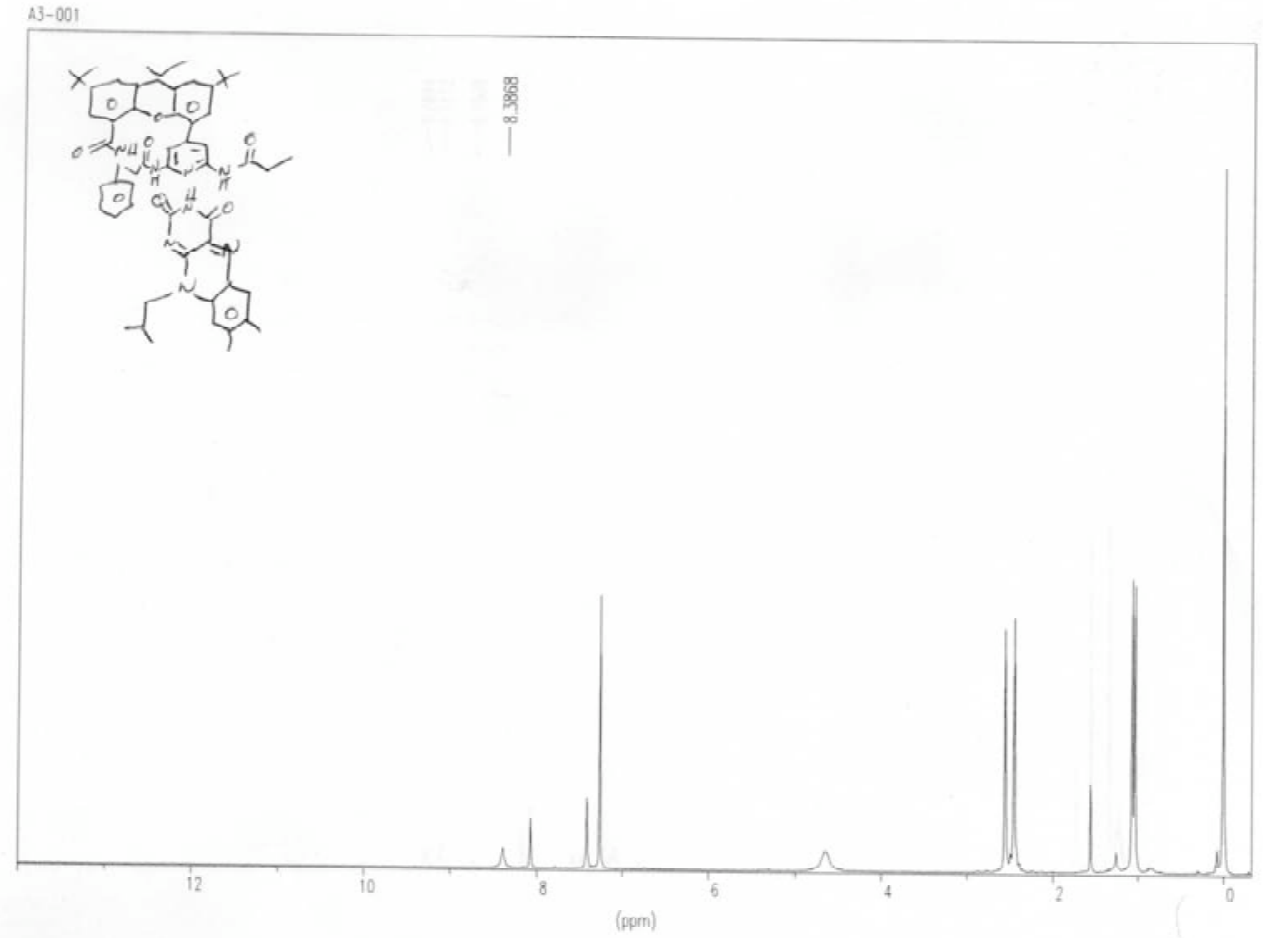

Isobutyl flavin "host" (alone) 


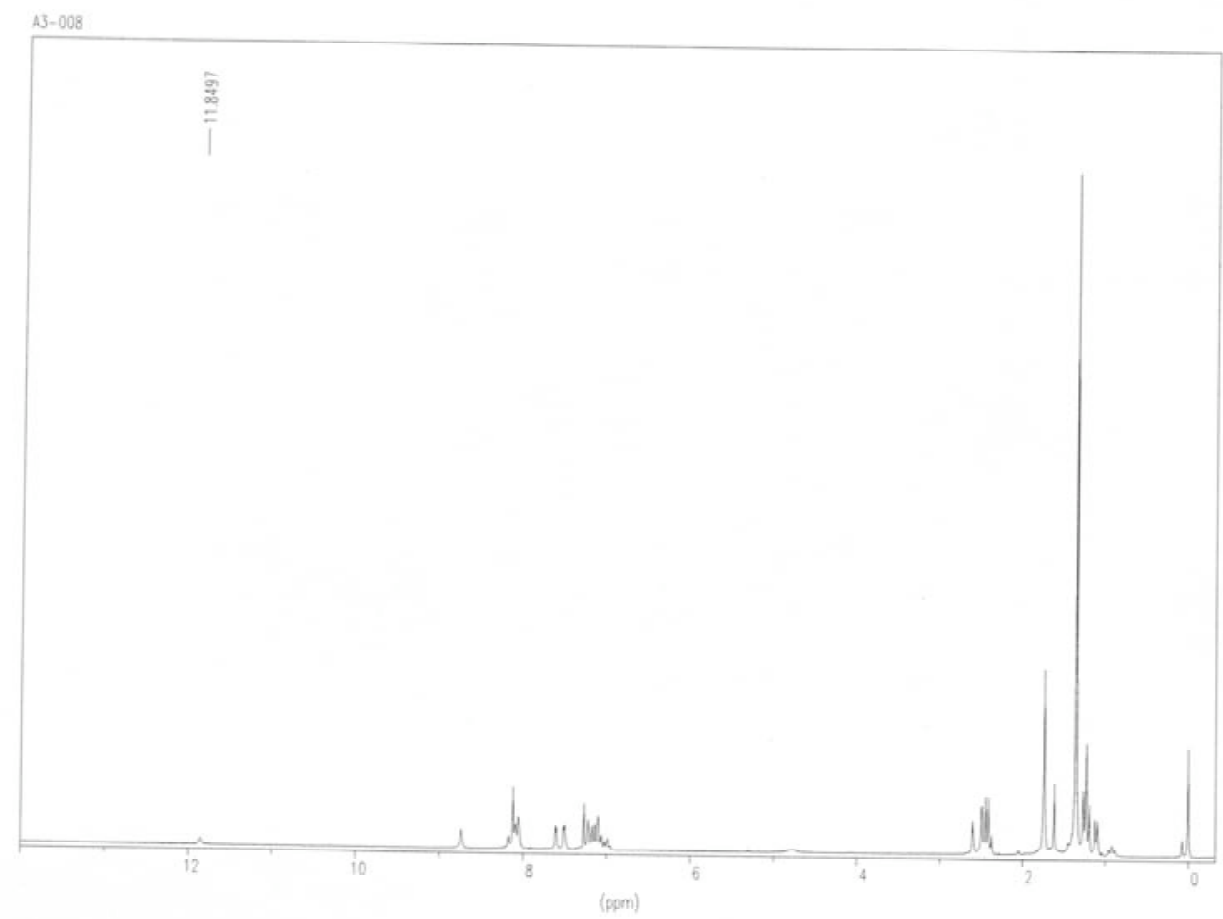

Flavin with eq. of "guest" compound 14a, (phenyl-DAP)

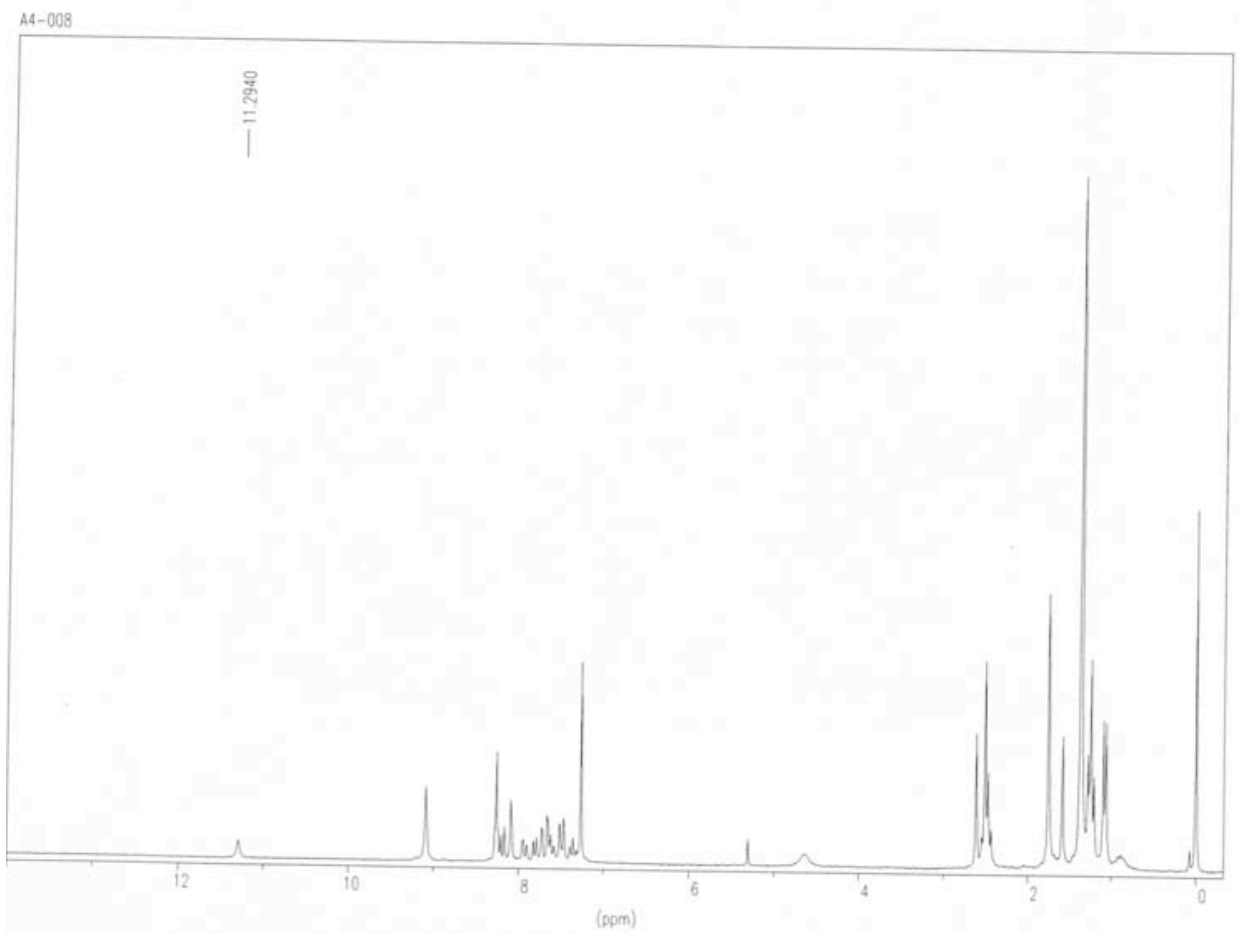

Flavin with eq. of "guest" compound 14c (anthracyl-DAP) 
Electrochemical data (Square Wave Voltammetry)

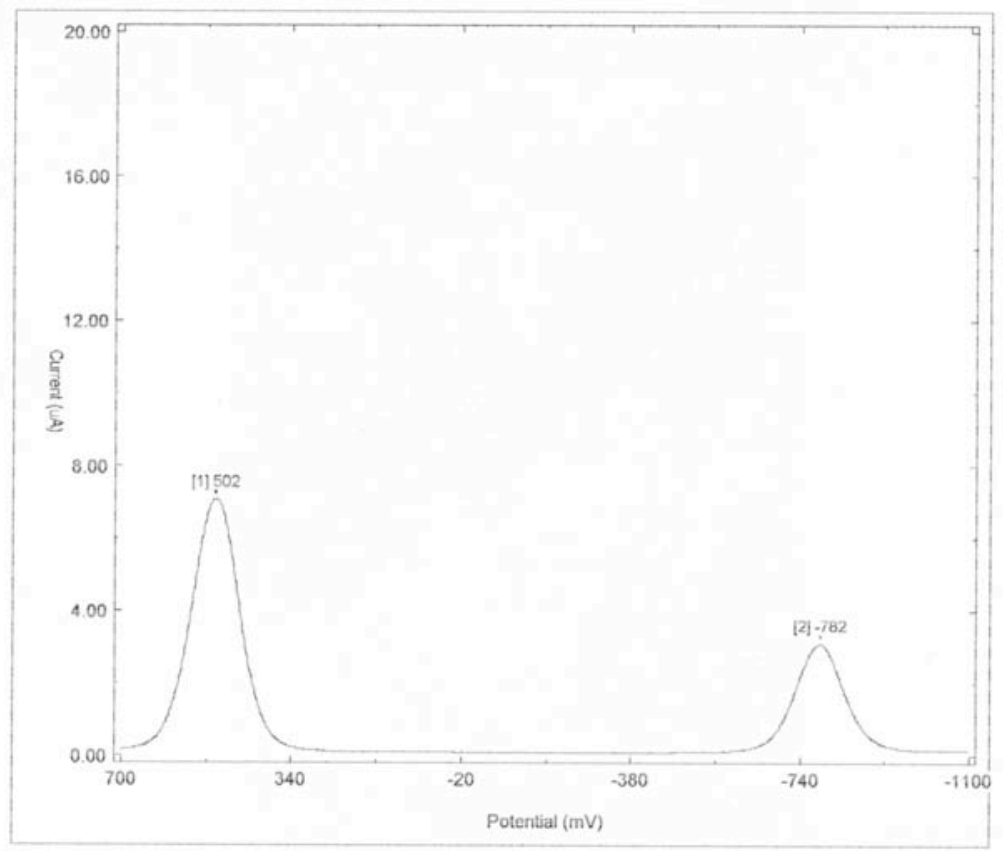

Flavin alone

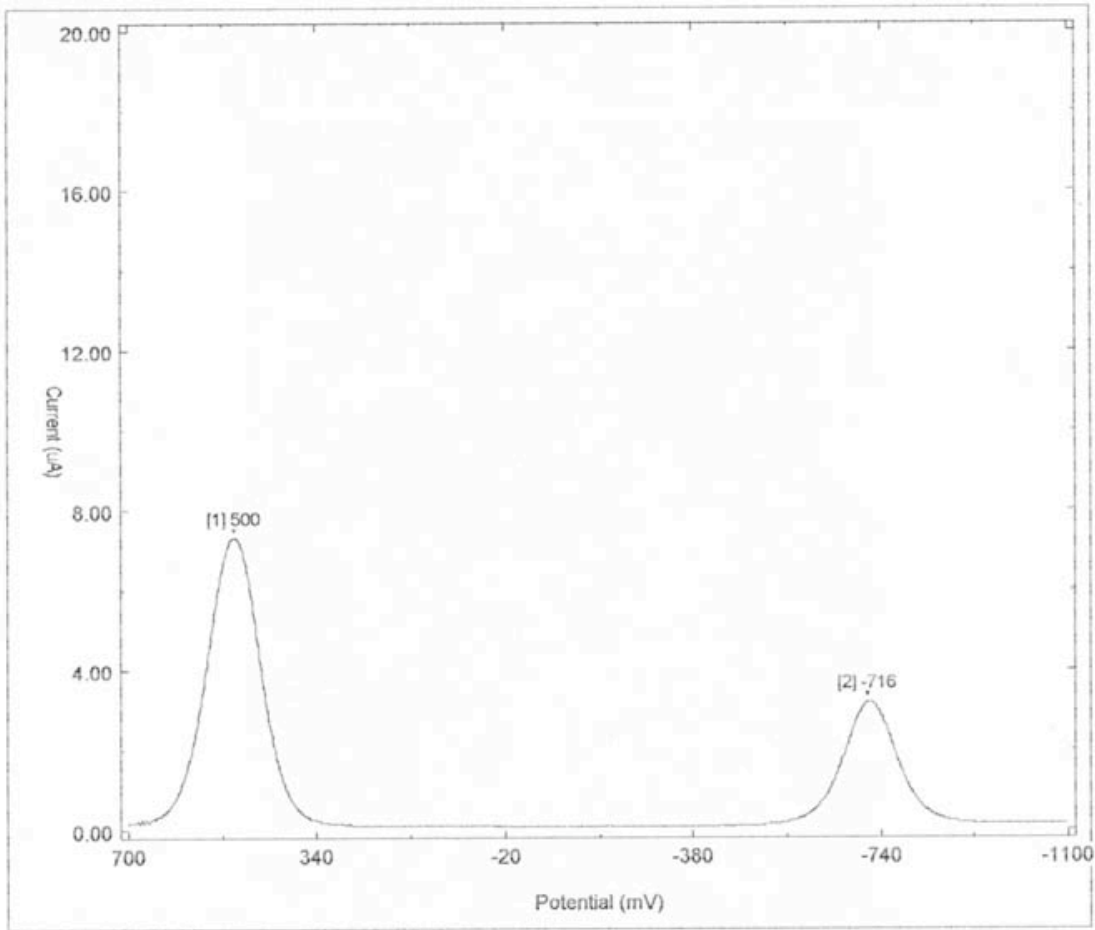

Radical anion of flavin upon addition of compound 14a (phenyl-DAP) 


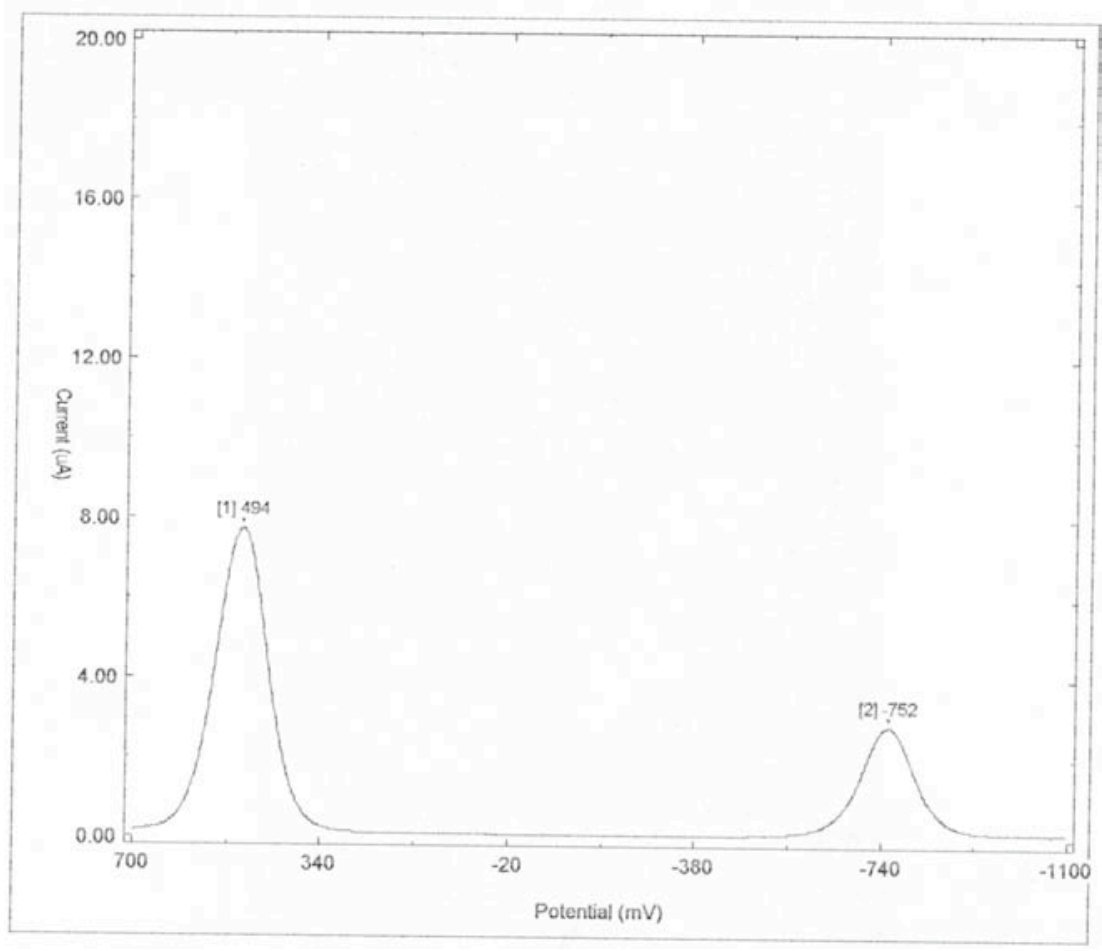

Radical anion of flavin upon addition of compound 14b (phenyl- $p$-thiomethyl-DAP)

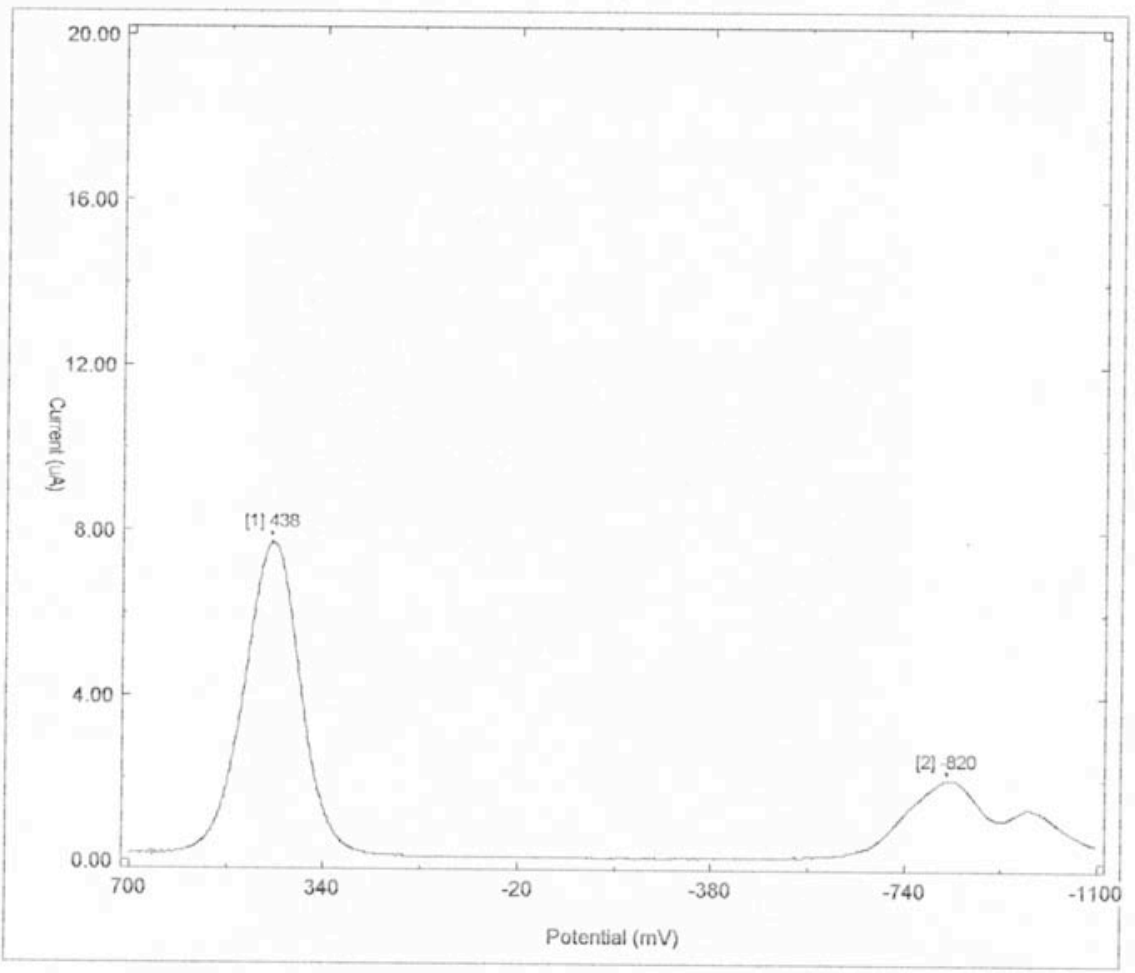

Radical anion of flavin upon addition of compound 14c (anthracyl-DAP) 